\title{
Fedra y los dioses (Eurípides, Racine, Unamuno)
}

\author{
José Manuel LOSADA GOYA \\ Universidad Complutense \\ Departamento de Filología Francesa \\ jlosada@filol.ucm.es
}

Recibido: 9 de julio de 2010

Aceptado: 22 de octubre de 2010

\section{RESUMEN}

El sentimiento trágico, encarnado por el personaje de Fedra en la obra de Eurípides, surge de la relación problemática entre libertad y destino. Las reescrituras de Racine y Unamuno enriquecen dicha tensión con nuevos matices. Este artículo analiza la relación entre la libertad y el destino a la luz del cristianismo y la presencia de lo apolíneo y lo dionisíaco en las tres versiones del mito.

Palabras clave: Fedra, Eurípides, tragedia, Racine, Unamuno, Nietzsche, cristianismo, jansenismo, Apolo, Dioniso, mito, Dios.

\section{Phèdre et les dieux (Euripide, Racine, Unamuno)}

\section{RÉSUMÉ}

Le sentiment tragique, incarné par le personnage de Phèdre dans la pièce d'Euripide, est issu du rapport de forces entre liberté et destin. Les réécritures de Racine et Unamuno enrichissent cette tension avec de nouvelles nuances. Cet article analyse la relation entre liberté et destinée à la lumière du christianisme et la présence de l'apollinien et du dionysiaque en tant qu'éléments communs aux trois versions du mythe.

Mots clés: Phèdre, Euripide, tragédie, Racine, Unamuno, Nietzsche, christianisme, jansénisme, Apollon, Dionysos, mythe, Dieu.

\section{Phaedra and the gods (Euripides, Racine, Unamuno)}

\begin{abstract}
Tragic emotion, embodied by the character of Phaedra in the Euripides play, has its origin in the problematic relationship between freedom and destiny. Such tension is enriched with fresh nuances in the rewritings of the Euripides play by Racine and Unamuno. This article analyzes the relationship between freedom and destiny from a Christian point of view, and explores the Apollonian and Dionysian as common elements present in the three versions of the myth.
\end{abstract}

Key words: Phaedra, Euripides, tragedy, Racine, Unamuno, Nietzsche, Christianity, Jansenism, Apollo, Dionysus, myth, God. 
En el mundo del orden ideado por Sócrates y Platón, el conocimiento mueve a la voluntad y conduce a la virtud; solo los ignorantes comenten los vicios y reciben en consonancia el justo castigo por su desorden. Existe otro mundo donde quienes conocen son precisamente quienes caen en el vicio. También en estos casos hay desorden, cuyo restablecimiento es posible de dos maneras: por medios normales o por medios anormales (Guicharnaud: 143). La representación de esta recuperación del orden recibe respectivamente el nombre de comedia o tragedia.

Los héroes de las tragedias griegas saben en qué consiste el bien, desean realizarlo pero, no obstante, cometen el mal. Su voluntad, buena en principio, es aplastada por una voluntad ajena: la divina. La pasión de uno o varios dioses impone su capricho al héroe: la pasión exterior y superior triunfa sobre la pasión interior e inferior. Es lo que se conoce con el nombre de destino o fatum. Lo trágico de este fatalismo no es que los hombres y las mujeres perpetren inconscientemente el mal, sino su propia conciencia del mal que odian y sin embargo hacen. En su continua agonía, los personajes contemplan su libertad, una libertad que aumenta el abanico de posibilidades de obrar el mal sin añadir ninguna de obrar el bien: estos ratones pueden optar entre diversas salidas, pero saben que al otro lado les espera el gato. De ahí la intensidad del sufrimiento: el dilema de los personajes trágicos reside en su libertad.

Este dilema del destino insoslayable no reduce la tragedia a mera necesidad. Aristóteles reclama la necesidad como una cualidad de los caracteres y de la estructuración de los hechos en la tragedia (54a34-35; 1974: 180), pero esta necesidad no es sinónimo de determinismo. La necesidad como automatismo determinista conduciría a una imperturbabilidad ajena al sentimiento trágico. En efecto, si el mecanismo trágico solo puede actuar en una dirección, al personaje le bastaría dejarse llevar, sufrir estoicamente los embates del destino y esperar tranquilamente el desenlace ineludible. De modo paradójico, la certidumbre de lo inevitable aportaría un alivio inhibidor que anula el sentimiento trágico. Por eso Henri Gouhier afirma con contundencia:

Il y a dans la fatalité deux éléments: la nécessité et la transcendance. Ce qui est tragique en elle, ce n'est pas la nécessité: la fatalité est tragique malgré la nécessité (1997: 48).

Necesidad trascendente es el término clave. La trascendencia como alternativa a la inmanencia implica la exterioridad, la apertura a un orden ajeno al puro determinismo. En el orden de la necesidad trascendente, diverso del sistema material que constituye nuestro universo, solo hay trascendencia de la necesidad en relación con seres libres: Il n'y a donc pas de fatalité sans liberté. Il n'y a donc pas de tragédie sans liberté (ibid.: 49). Gouhier, que aquí solo se refiere a la tragedia clásica y sus derivaciones posteriores, persigue con estas fórmulas evitar la identificación entre fatalismo y determinismo. Un ejemplo palmario: Edipo no pretende ni matar a su padre ni casarse con su madre, pero lo hace movido por el destino, que aplasta una voluntad que quería otro destino.

A esta relación entre tragedia, destino, necesidad y libertad es preciso, creemos, añadir un elemento: la conciencia. En realidad, solo hay que dejarlo explícito: sin conciencia no hay libertad. El héroe tiene la conciencia de poder elegir entre dos 
caminos, y también la convicción dolorosa de haber elegido el más funesto. Pero no por ello es menos libre: la fatalidad trágica es trascendente (la «fatalidad» inmanente a este mundo, la fatalidad que suprime la libertad, no es tal, sino determinismo).

En consecuencia, cabría definir la tragedia griega como sigue: situación consciente y dolorosa del héroe confrontado con un dilema cuyas soluciones, aun cuando afirman su libertad, se muestran nefastas porque restablecen por medios catastróficos el orden preestablecido por la voluntad de los dioses y violentado por la voluntad de dicho héroe.

Edipo, Antígona, Orestes, Electra o Efigenia encarnan situaciones trágicas: todos ellos saben lo que deben hacer en sus diversas circunstancias, pero también saben que el desenlace será desastroso porque así lo deciden las divinidades inflexibles. Fedra es uno de los personajes que mejor sintetiza el sentimiento trágico. En la obra de Eurípides, Hipólito, esta hija de Minos y Pasifae, desposada con el rey Teseo, experimenta el amor por Hipólito, su hijastro. Consumida por su pasión, querría morir. Su nodriza, para sacarla de su estado de postración, propone revelar al joven el secreto. La reina teme las nefastas consecuencias de esta revelación, pero accede debido a la debilitación de su razón y sus recursos psíquicos. El resultado es contrario a sus esperanzas. La reina, deshonrada, expulsa a su nodriza y se ahorca, no sin antes, con objeto de salvaguardar su decencia, difamar en unas tablillas al joven (le culpa de violación). Teseo, crédulo, maldice a su hijo, que muere. El elemento trágico reside en el intenso y desesperado sufrimiento de la reina a pesar de su libertad para contradecir el destino. La heroína lucha con denuedo contra su pasión incestuosa, hasta que constata la futilidad de toda resistencia: ella no es sino el instrumento de la diosa Afrodita, que la utiliza para vengarse del menosprecio del cazador Hipólito.

El caso de los héroes de buen número de los dramas modernos es distinto. También ellos conocen el bien, desean realizarlo y cometen el mal que detestan. También, como en el caso griego o romano, los dioses o la fortuna imponen su voluntad, la pasión exterior y superior triunfa sobre la pasión interior e inferior de los humanos. Sin embargo, la voluntad de los personajes no es aplastada sino puesta a prueba con diversos resultados. Tras el humanismo cristiano, es imposible ignorar el nuevo concepto de libertad humana. Segismundo, en La vida es sueño, ocupa por vez primera el trono y evidencia con sus fechorías que los astros no habían errado en sus pesimistas presagios. Vuelto a su prisión tras el efecto de un somnífero, al despertar se convence de que su reinado no ha sido más que un sueño. Pero la revuelta militar le repone sobre el trono $\mathrm{y}$, ante su padre humillado, con su clemencia da pruebas de que es posible contradecir el destino.

Paralelamente, otro número nada desdeñable de dramas modernos presenta casos en que la voluntad es asfixiada por la pasión desordenada. Esto ocurre sobre todo en obras cuyo argumento es herencia de la antigüedad. La protagonista de la tragedia Phèdre de Racine se sabe hija de una madre víctima del odio de Venus. A diferencia de la heroína de Eurípides, la de Racine está fuertemente marcada por su sangre miserable; de ahí su abyección por el amor hacia su hijastro. Convencida de su culpabilidad, nueva divergencia con el modelo griego, procura luchar con todas 
sus fuerzas: persigue encarnizadamente a su hijastro para provocarle al odio, suplica la ayuda y benevolencia de los dioses (En vain sur les autels ma main brûlait l'encens, I, III, 284; 1982, t. II: 292). Pero el destino es más fuerte: el encuentro con su objeto de deseo, después de serle anunciada la defunción (solo aparente) de su esposo, la deja sin recursos y la empuja a revelar su amor indomable (Tu $m$ 'as trop entendue, II, V, 670; ibid.: 306). Instantes después llega el desmentido de la noticia: Teseo no ha muerto. Pero ya es tarde para borrar e ignorar lo dicho. Deshonrada ante su hijastro, deja que su nodriza lo calumnie ante Teseo. Poco después se arrepiente y formula el propósito de limpiar la fama de Hipólito. Pero llega a sus oídos el amor secreto entre el príncipe y Aricia, una princesa enemiga reducida a la esclavitud: la ira de los celos la punza de modo irresistible y la reina consiente en el engaño del rey. Sin embargo, su propia conciencia la acusa de nuevo y Fedra se dispone a la purificación: maldice a su nodriza, se envenena con el fin de expiar sus culpas y rendir homenaje a los dioses y, finalmente, confiesa a Teseo su crimen (Non. Thésée, il faut rompre un injuste silence, V, VII, 1617; 340).

Racine declaró que nunca había escrito una tragedia donde la virtud fuera tan evidente. Es cierto que su Fedra, conforme a la Poética de Aristóteles (54a16-22; 1974: 179) y a diferencia de los principales modelos griego y latino (Eurípides y Séneca), no es del todo culpable, ni del todo inocente (prefacio, 1982: 277), y que, horrorizada por su pasión, prefiere morir a confesársela a alguien (ibid.). No es menos cierto que su Fedra es jansenista.

El jansenismo es una doctrina que sostiene el carácter limitado de la libertad humana en su relación con la gracia divina. El concilio de Trento había reafirmado los dogmas tradicionales sobre la gracia: predestinación (Dios conoce de antemano nuestro destino) y eficacia (Dios confiere al hombre un poder efectivo para hacer el bien). Dejaba, sin embargo, abierto el problema de la conciliación entre la gracia y la libertad humana. Posteriormente, el teólogo jesuita Luis de Molina (1536-1600) defendió en su libro De liberi arbitrii cum gratice donis concordia (1588, traducido al francés bajo el título Accord du libre arbitre avec les dons de la grâce divine) su teoría de la gracia suficiente: esta ayuda basta para que el hombre obre bien. En una tesis diametralmente opuesta, el teólogo flamenco Cornelius Jansen (Jansenius) sostuvo en su libro Augustinus (1640, de publicación póstuma) sus ideas sobre la gracia eficaz: después del pecado de Adán (que contaba con una gracia divina y una naturaleza perfecta), la humanidad ha quedado irremediablemente corrompida. Desde esta caída, nuestra voluntad se ve en exceso atraída por la concupiscencia (deseo de dominar, de saber y de sentir): está inclinada necesariamente hacia el mal hasta el punto que toda acción que haga es pecaminosa. Ahora bien, Jansenio reconoce que la necesidad de pecar es incompatible con la libertad. Con objeto de salvar el libre arbitrio, el teólogo recurre a dos expedientes. En primer lugar, afirma, nuestra voluntad no está determinada a cometer tal o cual pecado, aunque no puede evitar pecar (la libertad reside en la elección del pecado). En segundo lugar, si contamos con la gracia, Dios moverá nuestra voluntad hacia el bien, aunque en ese caso el acto virtuoso no podrá atribuirse a nuestra voluntad, sino a la gracia eficaz divina (la libertad reside en la petición del auxilio divino). En fin, Dios, conocedor de los méritos que tendrán los hombres antes incluso de crearlos, concede su gracia 
solo a sus elegidos (Journet: 38-44 y 54-56). Con una fórmula gráfica, aun a riesgo de rayar con el simplismo, diríamos que el jansenismo es una posibilidad formal de permanecer en el seno de la Iglesia católica con tesis de la Reforma. En lo que al teatro se refiere, la doctrina de la incapacidad humana para evitar el pecado de modo absoluto y de la predestinación final al margen de las propias obras introduce al jansenismo dentro del universo del fatalismo trágico.

La obra de Racine, educado en Port-Royal durante su infancia y defensor del monasterio en su madurez, refleja en buena medida la adopción de estas doctrinas. Así, Fedra es libre en la elección de sus desmanes: se escuda tras la responsabilidad de Enone, perpetra un crimen contra Hipólito, engaña a Teseo. Sin embargo, la reina no evita estos actos: una voluntad superior, la marca de su ascendencia, se impone fatídicamente: Puisque Vénus le veut, de ce sang déplorable / Je péris la dernière, et la plus misérable (I, III, 257-258; 1982: 291). Predestinada a obrar el mal, Fedra vislumbra al final una escapatoria: confesar su pecado, con la tenue esperanza de atraerse la comprensión de su marido (Teseo-Dios) y atemperar así las desastrosas consecuencias de sus actos. Al decir de Ortega, toda obra jansenista lleva siempre en su fondo un sedimento de desesperación religiosa, de suicidio de la razón (1937: 96): por desesperación, Fedra considera su culpa imperdonable, por desesperación, declara su amor a Hipólito, por desesperación, en fin, provoca su muerte y se la da a sí misma.

Fedra, tragedia de Unamuno, modifica considerablemente el marco de los modelos clásico y francés. Del original solo conserva los nombres de Fedra e Hipólito. La nodriza se llama aquí Eustaquia, el marido, Pedro, y un médico amigo, Marcelo. Como la Fedra de Racine, la de Unamuno se sabe marcada por su ascendencia materna (Dime, ¿luchó ella? [...] Y dime, ¿venció acaso? I, 1; 1987: 191). Entre la resignación de la nodriza y la acusación tácita del médico, ella recurre a la ayuda celeste, que no parece llegar. Para su desgracia, la imprudencia de su marido desencadena el desastre. Más amante y odiosa que nunca, Fedra constata cómo se debilitan su fe y su razón. Al final, cuando su propia conciencia la inculpa, entre rezos y espasmos por el envenenamiento, dispone todo para recuperar la paz perdida: confiesa en una carta su crimen a Pedro para alcanzar el perdón de la Virgen de los Dolores.

Fiel a la tradición, Unamuno combina la pasión interior de la protagonista con la pasión exterior de la herencia, aquí personalizadas respectivamente por la resignación o renuncia ante lo inevitable de la nodriza y la recriminación de Marcelo (Ortega y Gasset, 1937: 247). En palabras de Unamuno, Fedra adquiere aquí rasgos cristianos (exordio: 186). No obstante, un fatalismo omnipresente, aun cuando no provoque la asfixia de la voluntad de la heroína, la debilita considerablemente en aras de la afiliación trágica adoptada.

Un aspecto determinante de esta obra es el vitalismo que la impregna. La Fedra unamuniana es un caso paradigmático de surgimiento de lo vital impulsivo en el seno de la racionalidad (ed. Paulino, introd.: 64). Pocos años antes de la redacción de su tragedia, el autor había afirmado que la verdad racional y la vida están en contradicción (Ortega y Gasset, 1937: 83), que vivir es una cosa y conocer otra, y [...] acaso hay entre ellas una tal oposición que podamos decir que todo lo vital es 
antirracional, no ya solo irracional, todo lo racional, antivital. Y ésta es la base del sentimiento trágico de la vida (ibid.: 32). Esta dialéctica entre vida y razón, en oposición a Hegel y en línea con Schopenhauer, subyace en la mayoría de las versiones del mito de Fedra. El conflicto entre realidad y razón (en cualquiera de sus facetas: entre naturaleza y razón, entre sentimiento y razón, entre pasión y razón) forma el lecho sobre el que discurre la mayor corriente de la filosofía moderna desde Descartes: ¿cómo es posible conciliar el mundo material con el mundo espiritual?

La respuesta de un filólogo y filósofo vitalista puede ayudar a comprender mejor la estructura básica de muchas versiones del mito de Fedra. Según Nietzsche, el desarrollo del arte está ligado a la duplicidad de lo apolíneo y de lo dionisíaco (2000: 40). Apolo representa el arte del escultor, el mundo del sueño, de las bellas figuras y apariencias, de la necesidad y la comprensión, del vaticinio profético y la luz, de la mesurada limitación y el sabio sosiego libre de emociones salvajes, el principio de individuación de la esencia global mediante el espacio y el tiempo. Dioniso representa el arte no escultórico de la música, el mundo de la embriaguez, del espanto ante la desaparición de las formas de conocimiento de la apariencia, del éxtasis delicioso ante la infracción del principio de individuación, del poder narcotizante del vino y exaltador de la primavera, del placer mágico e inspirador de la naturaleza, de la libertad y la alegría, de la armonía universal del Uno primordial (ibid.: 41-47). El enfrentamiento entre estos dos mundos parece irreconciliable hasta que, finalmente, por un milagroso acto metafisico de la «voluntad» helénica, se muestran apareados entre sí, y en ese apareamiento acaban engendrando la obra de arte a la vez dionisíaca y apolínea de la tragedia ática (42). En efecto, en el arte imitativo de la tragedia se dan cita la perfección apolínea y la embriaguez dionisíaca: el artista puede al fin contemplar, de forma simultánea y en una imagen onírica simbólica, la unión fundamental de ambos mundos (49).

Este proceso, que de algún modo se da en toda tragedia, Fedra lo ejemplifica a la perfección. Lo demuestran algunas referencias explícitas en la obra griega: frente a Hipólito, que rinde homenaje de virtud y castidad a Ártemis, el coro describe a la reina afligida y sufriente, poseída por Pan (divinidad de la potencia sexual), por Hécate (divinidad de la magia), por los coribantes (sacerdotes que, entre paroxismos orgiásticos, acompañaban a Cibeles). Pero, incluso más allá de las recurrencias formales, nuestras tres versiones ilustran en el personaje de la heroína cuanto es necesario para constatar la fusión de los mundos apolíneo y dionisíaco.

En primer lugar, el elemento apolíneo. En las tres tragedias Fedra recapacita y procura refrenar sus instintos. En la de Eurípides, apenas ha desvelado su secreto, la heroína se arrepiente de la indiscreción (¡Desgraciada de mi! ¿Qué he hecho? ¿Por dónde me desvié de mi sano juicio?) y experimenta el rubor pudoroso (Mi rostro se ha vuelto de vergüenza): ella misma es quien procura entrar en razón y moderar sus sentimientos desbocados. En la de Racine, la protagonista multiplica sus sacrificios para reprimir sus impulsos y recuperar su raciocinio (Allí estaba Venus y las temibles pasiones que infunde, tormentos inevitables con los que persigue a mi raza. Mediante asiduos votos crei poder desviarlos: erigi un templo a Venus y me ocupé de embellecerlo. Rodeada a todas horas de víctimas para el sacrificio, 
buscaba en sus entrañas mi razón extraviada). En la de Unamuno, para volver al orden y la razón, Fedra recuerda el amor de su marido (Fui vencida por su generosidad) y recurre al auxilio del cielo ( $A$ [la Virgen Santísima] pido ayuda y consuelo en mi aflicción).

En segundo lugar, el elemento dionisíaco. En las tres obras Fedra irrumpe en escena presa de una desorbitada pasión amorosa. En la pieza de Eurípides, la reina siente con fuerza los impulsos de su naturaleza más instintiva. De poco le sirven sus luchas por aplacar la intensidad de su sentimiento: ningún razonamiento puede mitigar la espontaneidad de la atracción que sobre ella ejerce el hijo de la amazona. Por eso aparece delirante (;Llevadme a la montaña!), enfermiza hasta el extremo (;Qué débil y agotado tiene el cuerpo!), evocadora del dios mismo del éxtasis (desdichada hermana, esposa de Dioniso). En la pieza de Racine, además, afirma su condición nocturna (Me siento deslumbrada al ver la luz del día), por su alienación amorosa (Estoy poseida por la furia del amor) y por el ímpetu que la sedujo (Lo vi, me sonrojé y palidecí luego). En la pieza de Unamuno, se confirma su impotencia mental (Eustaquia: ¿no se te quita eso de la cabeza, Fedra?), su emoción visceral (Empezó llamándome «madre». ¡Madre! ¡Qué nombre tan sabroso! ¡Cómo remeje las entrañas! [...] Una ola de fuego me labra la carne toda. [...] iEs como una llovizna continua, cala hasta el tuétano!), su embriaguez absoluta (¿Qué más bebedizo, di, que su aliento esparcido por toda esta casa?).

La evolución de los acontecimientos pone de manifiesto el fracaso de los afanes de Fedra por zafarse al mundo de los instintos. Solo al final, en las tres versiones, se da la simbiosis de los mundos apolíneo y dionisíaco; cuando las piezas tocan a su fin, todo concurre para restablecer de algún modo el orden inicial. En Hipólito, Ártemis, la diosa preferida del joven cazador, se revela a Teseo, describe la verdad de los hechos, devuelve el honor al hijo fallecido y, en la medida de lo posible, también a la madre. En Phèdre, la reina envenenada se presenta ante su marido para relatar la verdad y defender la inocencia del hijo. En Fedra, la moribunda entrega, desde el lecho de muerte, una carta para revelar toda la verdad. En cualquiera de los casos se da una curiosa conjunción de las facetas apolínea y dionisíaca. Por un lado, tras el extravío y la alienación, la muerte de la protagonista simboliza la sumisión a las normas de la moral o de la sociedad: al desenfreno vergonzante sobrevive la imposición de unas normas, el imperio de la razón y la moderación de la virtud. Por otro lado, tras la muerte de la protagonista, las piezas se ven inundadas por una atmósfera de rehabilitación: en Eurípides, Ártemis muestra a Teseo la dignidad de [su] esposa, en Racine, la misma Fedra acomete una confesión heroica para [devolver] al día [...] toda su pureza y, en Unamuno, el mismo esposo la beatifica: ¡Después de todo ha sido una santa mártir! Tras la sumisión a las reglas de Apolo, la redención, otro de los distintivos de Dioniso.

El lector habrá distinguido la libertad trágica de la libertad moderna, basada en principios, particularmente desarrollados por el cristianismo, de posibilidad de elección responsable entre el bien verdadero y el mal. También habrá tenido presente que su conocimiento de las tragedias y sus mitos le pone en una situación muy distinta de la experimentada por los personajes, que nada saben, a priori, del desenlace de sus historias. En efecto, la necesidad trascendente es solo aplicable a la 
tragedia clásica: en el cristianismo propiamente dicho (más precisamente, el católico, referente primordial de Racine y Unamuno) no hay tragedia. La libertad es precisamente un don divino, y la responsabilidad resulta de la libre cooperación del sujeto a la gracia. Por contraposición, las tragedias francesa y española (a pesar del referente de sus autores) evidencian su carácter clásico: el pensamiento jansenista y el «sentimiento trágico de la vida», incompatibles con esa doctrina cristiana, parecen moverse más bien en el marco del fatalismo grecorromano. Paralelamente, las tres obras mantienen una estrecha sintonía con la fusión trágica de los elementos apolíneo y dionisíaco. No sería muy descabellado lanzar puentes de conexión entre estos dos elementos por un lado y el pensamiento jansenista según Racine y el «sentimiento trágico de la vida» según Unamuno por otro.

\section{REFERENCIAS BIBLIOGRÁFICAS}

ARISTÓTELES (1974): Poética, ed. trilingüe V. García Yebra, Gredos. EURÍPIDES (1998): Hipólito in Tragedias, Cátedra, t. I, ed. J.A. López Férez. GOUHIER, H. (1997): Le Théâtre et l'existence, Vrin.

GUICHARNAUD, J. (1963): Molière, une aventure théâtrale, Gallimard.

JOURNET, C. (1979): Charlas acerca de la gracia (Entretiens sur la grâce), Patmos, 1979.

LOSADA, J.M. (1993): «El sentimiento trágico en el teatro clásico francés: el caso de Phèdre» in Thélème $\mathrm{n}^{\mathrm{o}} 4,101-118$.

MOELLER, C. (1963): Sabiduría griega y paradoja cristiana, Juventud.

NIETZSCHE, F. (2000): El nacimiento de la tragedia, Alianza.

ORTEGA VILLARO, B. (1995): "Los personajes secundarios del mito de Fedra" in Mito y personaje, María Luisa Lobato et al. eds., Ayto. Burgos, 241-250.

ORTEGA Y GASSET, J. (1937): Del sentimiento trágico de la vida, Austral.

RACINE, J. (1982): Théâtre complet, ed. J.-P. Collinet, Gallimard, «Folio», 2 vol.

— (1985): Andrómaca. Fedra, ed. E. Náñez, Cátedra.

UNAMUNO, M. (1987): La esfinge. La venda. Fedra, ed. J. Paulino, Castalia. 